\title{
Folato Sérico y Eritrocitario en el Lactante
}

\author{
Dr. Manuel Olivares G. ${ }^{1}$, T.M. Mary Anderson 1, T.M. Sandra Llaguno A. ${ }^{1}$ \\ Dr. Abraham Stekel G.1
}

Serum and red blood cell folic acid levels in infants

\begin{abstract}
A cohort of 149 infarts was followed longitudinally. All infants were born at term and originated in the South and Eastern areas of Santiago, of lower socioeconomic levels. Serum and red cen folate levels were measured in a subsample at 3,9 and 35 months of age. The measurement at 3 months showed high levels (RBC folate $452 \mathrm{ng} / \mathrm{ml}$ ) which dropped at 9 months (RBC folate $358 \mathrm{ng} / \mathrm{ml}$ ) to risc again at 15 months ( $R B C$ folate $397 \mathrm{ng} / \mathrm{mll}$ ).

The folate levels determined at any age showed higher average values than those found in a group of normal adults. In any event, in the infants studied, there was a low prevalence of subnormal folate values $(9 \%$.
\end{abstract}

El lactante por su elevada velocidad de crecimiento y bajo aporte dietario de hierro y ácido fólico está sometido a un mayor riesgo de experimentar un déficit de estos nutrientes. Diversos estudios realizados en nuestro pais muestran que un 62 a $75 \%$ de los lactantes de baja condición socioeconómica presentan una deficiencia de hierro ${ }^{1-2-3-4}$. Comparativamente no existe información sobre la prevalencia de la deficiencia de ácido fólico en este grupo etario.

El propósito de este trabajo es determinar, en un grupo de lactantes de baja condición socioeconómica, la prevalencia de la deficiencia de ácido fólico y la variación que experimentan los valores de folato sérico y eritrocitario durante los primeros 15 meses de vida.

\section{MATERLAL Y METODOS}

En dos consultorios ubicados en las áreas Sur y Oriente de Santiago, se seleccionó un grupo de 149 lactantes de tres meses de edad, que cumplian con los siguientes requisitos: eutróficos con un peso de nacimiento superior a $2.500 \mathrm{~g}$., no haber recibido hematínicos a transfusión sanguínea y estar sanos al momento del ingreso.

Las madres de estos sujetos provenian en su mayoría de un estrato socioeconómico bajo y no habian recibiđo suplementación con ácido fólico durante su embarazo.

Los lactantes elegidos fueron seguidos longitudinalmente, realizándoseles mensualmente un control clínico y antropornétrico. En un sub-grupo elegido al azar y previa autorización de los padres, se obtuvo en ayunas una muestra de sangre

1 Unidad de Hematología. División de Nutrición Humana y Ciencias Médicas. Instituto de Nutrición y Tecnología de los Alimentos, Universidad de Chíle. venosa, determinándose a los 3,9 y 15 meses de edad los niveles de folato sérico y eritrocitario, mediante un ensayo biológico con lactobacillus casei $^{5-6}$.

Al ingreso la mayoría de los niños estaba alimentado en forma total o parcial con leche materna, recibiendo al destete una leche en polvo completa (PuritaR). La introducción de otros alimentos se realizó de acuerdo al siguiente esquema: jugos cítricos al mes de edad, frutas a los dos meses, carne y vegetales cocidos a los cuatro meses.

Dado el hecho que los valores de folato sérico y eritrocitario presentan una distribución asimétrica, la que se normaliza al efectuar una transformación logarítmica, los resultados se expresaron como promedios geométricos?.

En este trabajo se utilizó como criterio de anormalidad un folato sérico $<3 \mathrm{ng} / \mathrm{m}^{3}$ y un folato eritrocitario $<160 \mathrm{ng} / \mathrm{ml}^{6}$.

\section{RESULTADOS}

En la Tabla 1 se aprecia, que en todos las edades estudiadas, los lactantes presentan valores de folato sérico y eritrocitario más altos que los obtenidos en un grupo de adultos. A los tres meses de edad se encuentran los niveles de ácido fólico nás elevados los que descienden a los 9 meses para recuperarse parcialmente a los 15 meses de vida.

En el grupo de niños estudiados se pudo tomprobar una baja prevalencia de deficiencia de ácido fólico (Tabla 2), encontrándose a los 9 meses el mayor porcentaje de sujetos con valores subnormales de folato sérico y eritrocitario.

\section{COMENTARIO}

El ácido fólico es un nutriente indispensable para el ser humano. La deficiencia de esta vitamina es capaz de producir una anomalía funcional y 
Tabla 1.

Fola to Sérico y Eritrocitario en el Lactante*

$\begin{array}{lcccc} & 3 \text { Meses } & 9 \text { Meses } & 15 \text { Meses } & \text { Adultos } \\ \text { Folato Sérico } & 15.8 & 13.1 & & 14.1 \\ \mathrm{ng} / \mathrm{ml} & (7.0-35.4) & (6.5-26.6) & (7.5-26.5) & (5.3-10.6) \\ & \mathrm{N}=72 & \mathrm{~N}=97 & \mathrm{~N}=84 & \mathrm{~N}=31 \\ \text { Folato Eritrocitario } & 452 & & & \\ \mathrm{n} g / \mathrm{ml} & (275-743) & (212-604) & (257-612) & (246-405) \\ & \mathrm{N}=51 & \mathrm{~N}=89 & \mathrm{~N}=81 & \mathrm{~N}=31\end{array}$

* Promedio geométrico y rango de 1 desviación standard.

N Número de sujetos.

Tabla 2.

$\%$ Lactantes deficientes en Folato

3 Meses 9 Meses 15 Meses

$\begin{array}{llll}\begin{array}{l}\text { Folato Sérico } \\ \text { <3ng } / \mathrm{ml}\end{array} & 0.0 & 2.1 & 1.2 \\ \begin{array}{l}\text { Folato Eritrocitario } \\ <160 \mathrm{ng} / \mathrm{ml}\end{array} & 3.9 & 9.0 & 2.5\end{array}$

morfológica de la médula ósea. Posteriormente se han descrito, en el lactante, otras alteraciones producidas por esta carencia, tales como: retardo del crecimiento ${ }^{9-10-11}$, alteraciones funcionales $\mathrm{e}$ listológicas del intestino delgad., 12 , retardo de la naduración cerebraj ${ }^{13}$ y una n.ayor frecuencia de infecciones ${ }^{14-15}$

El feto nace con un contenido de ácido fólico que es proporcional a la duración de la gestación. presentando el recién nacido niveles de folato sérico y eritrocitario muy elevados ${ }^{16 \cdot 17-18}$. En el periodo post natal se inicia un gradual descenso de los valores, los que alrededor de $\operatorname{los} 2$ a 3 meses se hacen incluso inferiores a los del adulto ${ }^{16-19-20}$ manteniéndose esta situación durante gran parte o la totalidad del primer año de vida. Esta caida obedecería al agotaniento de las reservas de ácido fólico determinada por un aumento de los requerimientos de este nutriente, asociado a un insuficiente aporte dietario. Ese descenso es menos pronunciado en los niños alimentados al pecho ${ }^{21-22-23}$ debido probablemente al mayor contenido en folato de la leche materna $21 \cdot 24$.

A los 3 meses de vida, un número importante de nuestros lactantes estaba alimentado al pechó en forma total o parcial, to que explicaría los elevados valores de folato encontrados a esi edad; sin embargo por no disponer de determinaciones en el periodo post natal inmediato, no podemos descartar que este fenómeno también pudiera de- berse a un aumento de las reservas de folato adqui ridas por el recién nacido. Al disminuir la cuantía de la alimentación láctea materna se produciría el descenso de los valores, los que posteriormente se incrementan al tomar mayor importancia cuantitativa el aporte de folato derivado de la alimentación sólida.

Ante un aporte insuficiente de ácido fólico, se produce un descenso a valores subnormales de las concentraciones de folato sérico y eritrocitario. Primero cae el folato sérico ( 3 a 6 semanas) y más tardiamente lo hace el folato eritrocitario ${ }^{25}$. El nivel sérico se correlaciona con la ingesta de las últimas semanas, mientras que la concentración eritrocitario se correlaciona mejor con los niveles tisulares ${ }^{26}$.

En los lactantes estudiados, encontramos una baja prevalencia de valores subnormales de folato, por lo que pareciera que, ers nuestro medio, la deficiencia de ácido fólico es una causa poco frecuente de anemia nutricional en este grupo etario, no justificándose la implementación de programas destinados a prevenir esta carencia.

\section{RESUMEN}

Se siguió longitudinalmente un grupo de 149 lactantes de término de baja condición socjoeconómica, provenientes de las Areas Sur y Oriente de Santiago. En una submuestra se determinaron los niveles de folato sérico y eritrocitario a los 3,9 y 15 meses de vida. A los 3 meses se constataron concentraciones elevadas de folato sérico y eritrocitario, las que descendieron a los 9 meses para recuperarse parcialmente a los 15 meses. A todas las edades estudiadas, los lactantes presentaron valores de folato más altos que los de un grupo de adultos normales. En los niños estudiados se enconttó una baja prevalencia de valores subnormales de ácido fólico. 


\section{REFERENCIAS}

1 Winter, A, Taboada, H., Ducos, R., Norambuena, N., $V e r a, S$, y Delgado, $C$. Incidencia de anemia y lerropenia en el lactante chileno. Rev. Chil. Ped. 45: 1035. 1970.

2 Margozzini, J., Braw, M., Lanzkowsky, P., Valiente. S., Rosales, E., López, I., Covarrubias, E., Puratic, O y Aratuco, $G$.: Deficiencia de hierro en lactantes eu róficos del Area Norte de Santiago. Rev. Chil. Ped. 43: 9, 1972.

3 Winter, A., Taboada, H., Galofre, A., Waiz. 4. y Arteage, $M$. Prevalencia de anemia fenopriva y deficiencia de hierro en una población materno-infantil del Area Sur Oriente de Santiago de Chile, 1970. Rev. Chil, Ped. 45: 53, 1974.

4 Stekel. A, Olivares, M., López, I., Chadud, P., Castaño, G. y Amar, $M$. Implicancias nutrisionales de algunos cstudios de prevalencia de la carcncia de hierro en Chile. IV Congreso Chileno de Hematolouia. San. tiago, 1976.

5 Woters, A.H. and Molkin, D.L. Studies on the jolic acid activity of human serum. J. Cin. Path. 14: \$35, 1961.

6 Hoffrand, A.V., Beverly, F.A. and Mollin, D.L. Method of assay of red cell folate activity and the value of the assay as a test for folate deficiency. $J$. Clin. Path. 19: 17, 1966.

7 Weil, A. and Mouracher, E. Folic acid and pregnancy: is there a real problem?... Schweiz. Med. Wschr. 107 1943,1977

8 Herbert, $V$. Ascptic addition method for Lactobacillus casei assay for folate activity in human scrum. J. Clin. Path. 19: 12, 1966.

${ }^{9}$ Gandy, G. and Jacobson, W. Influence of folic acid on birth weight and growth of the ery throblastotic infant. II Growth during the first year. Arch. Dis. Child. 52: 7,1977 .

10 Gendy, G. and Jacobson, $W$. Influence of folic acid on bir th weight and growth of the exy throblastotic infant. III Effect of folic acid supplementation. Arch. Dis. Child. 52: 16, 1977.

11 Matoth, Y. Zehavi, I., Topper, E. and Klein, T. Folate rutrition and growth in infancy. Arch. Dis. Child. 54: $699,1979$.

12 Davidson, G.P. and Townley, RRW. Structural and functional abnormalities of the small intestine due to nutritional folic acid deficiency in infancy. Pediatrics 90: $590,1977$.

13 Arakawa, T., Mizumo, T., Honda, $Y_{.,}$Tamora. $T$. ,
Watanabe, A., Komatsushiro, M., Takagi, T., limuna, $\boldsymbol{K}$. and Yamonchi, $N$. Longitudinal study on maturation putterns of EEG basic waves of infants fed on milk from mother with low serum folate levels. Tohoku J. Exp. Med. 102: 81, 1970.

14 Friedman, R., McKenzie, D., Turnet, T. and Wittmann, $W$. Folic-acid deficiency in infantile gastroenteritis. S. Afr. J. Lab. Clin. Med. J0: 69, 1964.

is . Watoth. Y., Zamir, $R$, Bar-Shani, S. and Grossowicz. $v$. Studies on folic acid in infancy. Il. Folic and follnic acid blood levels in infants with diarshea, malnutrition and infection. Pediatrics 33: 694, 1964 .

16 Fanier, T.M. ond Tyas, J.F. Folic acid status in normal infants during the first year of life. Arch. Dis. Child. 41: 658,1966

17 Novarm, I., Rey, F., Polonovski, C. et Laplane, R. Acide colique serique en pediatrie. Resultats nosmaux et en puthologie. Arch. Franc. Ped. 25: 19, 1968.

${ }^{18}$ Gross, S., Kamen, B., Fana:off, A. and Caston, D. Foldte compartments during destational maturation. J. Pcdiatr. 96: 842, 1980.

${ }^{19} E k, J$. and Magnus, E. Plasma and red cell folacin in cow's milk fed infants and children during the first 2 years of life: The significance of boiling pasteurized cow's milk. Ant. J. Clin. Nutr. 33: 1220, 1980.

20 Matoth, Y., Pinkas, A. Zamir, R., Moonilen, F, and Groswowics, N. Studies on folic acid in infancy. I bloed levels of folic acid and folinic acid in healthy inficits. Pediatrit:s 33: 507, 1964

21 Macorh, Y., Pinkas, A. and Sroka, C.H. Studies on follic acid in infancy. HI. Folates in breast fed infants and thejs nothers.

22 Ek., J., and Magnus, E. Plasma and red blood cell folate in breast fed infants. Acta Paediatr. Scand. 68: $239,1979$.

23 Olivares, M., Anderson, M., Llaguno, S, and Stekel, $A$. Serum and erithrocyte folate in infancy: Effect of iron nutritional status and duration of breast feeding. Ped. Res. 15: 177, 1981 (Abstract).

24 Ford, J., Poster, J.W.G., Scott, K.J., Thompson, S.Y., Lee Marquand, J, and Truswell, A.S. Comparison of dried milk preparations for babies on sale in 7 European countries. Il. Folic acid, vitamin $B_{6}$, thiamin, riboflavin and vitamin E. Arch. Dis. Child. 49: 874,1974 .

25 Herben, $\boldsymbol{V}$. Biochemical and hematological lesions in folic acid deficiency. Am. J. Clin. Nutr. 20; 562, 1967.

26 Chanarin, I. The megaloblastic anaemias. Oxford and Edinburgh Blackwel, Seientific Publications, 1969. 